\title{
IMPLEMENTASI PENDIDIKAN LUAR SEKOLAH TERHADAP PEMBENTUKAN KARAKTER SISWA SEKOLAH DASAR
}

\author{
Kurnia Eka Wijayanti ${ }^{1}$ Yogi Akin ${ }^{1}$ Oyok Nurjatnika ${ }^{2}$ \\ Universitas Pendidikan Indonesia ${ }^{1}$ \\ SDN Leuwigajah Mandiri $1 \mathrm{Cimahi}^{2}$ \\ email : kurniaeka22@upi.edu
}

\begin{abstract}
Abstrak
Dalam penelitian ini membahas tentang peran outdoor education dalam mengembangkan karakter siswa. Pengembangan pendidikan karakter dapat dilakukan dimana dan oleh siapa saja, salah satunya dapat dilaksanakan melalui outdoor education. Penelitian ini bertujuan untuk mengkaji dan menemukan hasil implementasi pendidikan luar sekolah (outdoor education) terhadap pembentukan karakter siswa sekolah dasar. Luaran yang diharapkan dari penelitian ini adalah terwujudnya implementasi yang baik yang berfokus kepada pendidikan luar sekolah (outdoor education) terhadap pembentukan karakter pada siswa sekolah dasar. Penelitian ini menggunakan pendekatan kuantitatif dan kualitatif dengan metode eksperimen kuasi dengan desain nonequivalent pre test-post test control group design (pre test-post test dua kelompok). Subjek penelitian dipilih dengan teknik non-probabilitas dari sampel purposif (purposive sampling). Instrumen penelitian berupa angket yang dianalisis dengan teknik statistik yaitu ukuran gejala pusat dan Uji T berpasangan (paired t test), berdasarkan penghitungan diatas diperoleh $\mathrm{t}$ hitung $=4,67$ dan nilai $\mathrm{t}$ tabel $=1,743$ artinya hipotesis ditolak yang berarti bahwa terdapat implementasi positif yang signifikan dari pendidikan luar kelas (outdoor education) terhadap pembentukan karakter siswa sekolah dasar. Hasil penelitian siswa cenderung menggunakan atau memanfaatkan alat atau fasilitas di lingkungan kita tanpa harus membelinya sehingga perlu daya imajinasi dan kreativitas yang tinggi, kemampuan problem solving pada anak, menstimulasi perkembangan bahasa dan kemampuan verbal, mengembangkan keterampilan sosial, dan merupakan wadah pengekspresian emosi.
\end{abstract}

Kata Kunci : Implementasi, pendidikan luar sekolah, karakter 


\section{A. PENDAHULUAN}

Pendidikan luar kelas (outdoor education) merupakan aktivitas luar sekolah yang berisi kegiatan di luar kelas/sekolah dan di alam bebas lainnya, seperti: bermain di lingkungan sekolah, taman, perkampungan pertanian/nelayan, berkemah, dan kegiatan yang bersifat kepetualangan, serta pengembangan aspek pengetahuan yang relevan (Arief Komarudin, 2000). Pendidikan luar kelas tidak sekedar memindahkan pelajaran ke luar kelas, tetapi dilakukan dengan mengajak siswa menyatu dengan alam dan melakukan beberapa aktivitas yang mengarah pada terwujudnya perubahan perilaku siswa terhadap lingkungan melalui tahap-tahap penyadaran, pengertian, perhatian, tanggungjawab dan aksi atau tingkah laku. Pendidikan luar kelas mengandung filosofi, teori dan praktis dari pengalaman dan pendidikan lingkungan. Priest (1986) dalam Tri IL (2008: 5) menyatakan " Outdoor education is, an experimential method of learning by doing, which takes place primarily through exposure to the out-of-doors. In outdoor education, the emphasis for the subject of learning is placed on RELATIONSHIP: relationship concerning human and natural resources. Pendidikan luar kelas bertujuan agar siswa dapat beradaptasi dengan lingkungan dan alam sekitar dan, mengetahui pentingnya keterampilan hidup dan pengalaman hidup di lingkungan dan alam sekitar, dan memiliki apresiasi terhadap lingkungan dan alam sekitar. Aktivitas luar kelas dapat berupa permainan, cerita, olahraga, eksperimen, perlombaan, mengenal kasus-kasus lingkungan disekitarnya dan diskusi, penggalian solusi, aksi lingkungan, dan jelajah lingkungan (Vincencia S, 2006).

Pendidikan luar kelas bukan aktivitas fisik saja, Outdoor learning is learning, bukan sekedar bersenang-senang. Program pendidikan luar kelas yang bagus harus mencakup high impact activities. Kompetensi seseorang ditingkatkan melalui pengembangan pengetahuan, skill dan karakter dari yang bersangkutan. Untuk menghasilkan peak adventure, kegiatan dalam pendidikan luar kelas harus bisa mengeluarkan partisipan dari comfort zone mereka. Pendekatan Out-door learning menggunakan alam terbuka sebagai sarana. Proses pembelajaran menggunakan alam sebagai media dipandang sangat efektif dalam manajemen pengetahuan (knowledge management) dimana setiap orang akan dapat merasakan, melihat langsung bahkan dapat melakukannya sendiri, sehingga transfer pengetahuan berdasarkan pengalaman di alam dapat dirasakan, diterjemahkan, dikembangkan berdasarkan kemampuan yang dimiliki. Pendekatan ini mengasah aktivitas fisik dan aspek sosial anak dimana anak akan lebih banyak melakukan kegiatan-kegiatan yang secara tidak langsung melibatkan kerjasama antar teman dan kemampuan berkreasi. Aktivitas ini akan memunculkan proses komunikasi, pemecahan masalah, kreativitas, pengambilan keputusan, saling memahami, dan menghargai perbedaan. (http://www.plbjabar.com) 
Beberapa konsep yang melandasi pendekatan Out-door learning :

a. Pendidikan selama ini tidak menempatkan anak sebagai subjek

b. Setiap anak berkebutuhan khusus dan unik. Mereka mempunyai kelebihan dan kekurangan, sehingga proses penyeragaman dan penyamarataan akan membunuh keunikan anak. Keunikan anak yang berkebutuhan khusus harus mendapat tempat dan dicarikan peluang agar anak dapat lebih berkembang.

c. Dunia anak adalah dunia bermain, tetapi pelajaran banyak disampaikan tidak lewat permainan.

d. Usia anak merupakan usia yang paling kreatif dalam hidup manusia, namun dunia pendidikan kurang memberikan kesempatan bagi pengembangan kreativitas. Sedangkan elemen-elemen yang perlu diperhatikan dalam pendekatan Outdoor learning adalah : 1) Alam terbuka sebagai sarana kelas; 2) Berkunjung ke objek langsung; 3) Unsur bermain sebagai dasar pendekatan; 4) Guru harus mempunyai komitmen.

Selain itu pendidikan luar kelas juga mengembangkan kreativitas, komunikasi, kerjasama, motivasi diri, kompetisi, pemecahan masalah (problem solving) dan kepercayaan diri agar anak memiliki kepribadian yang bagus perlu diciptakan lingkungan yang kondusif. Anak akan tumbuh menjadi pribadi yang baik dan berkarakter jika tumbuh di lingkungan yang berkarakter pula. Ada tiga komponen yang membentuk karakter anak, yaitu: keluarga, sekolah dan komunitas, seperti komunitas sosial, fisik maupun lingkungan alam. Interaksi anak dan lingkungan alam yang dekat akan melahirkan kedekatan dan penghayatan terhadap kenyataan hidup. Penghayatan inilah yang membentuk cara pandang serta penghayatan akan totalitas cara pandang mengenai hidup yang mencerminkan karakter anak (Goleman, 2000: 407). Lebih lanjut Goleman menyatakan bahwa dalam membentuk karakter anak perlu memperhatikan beberapa hal. Pendidikan karakter adalah pendidikan budi pekerti plus, yaitu yang melibatkan aspek pengetahuan (cognitive), perasaan (feeling), tindakan (action). Menurut Thomas L, tanpa ketiga aspek ini, maka pendidikan karakter tidak akan efektif dan pelaksanaannya pun harus dilakukan secara sistematis dan berkelanjutan. Dengan pendidikan karakter, seorang menjadi cerdas emosinya. Kecerdasan emosi adalah bekal penting dalam mempersiapkan anak menyongsong masa depan karena dengannya seseorang anak akan dapat berhasil dalam menghadapi segala macam tantangan, termasuk tantangan untuk berhasil secara akademis.

Hasil pengamatan penulis dan minimnya penelitian yang dilakukan di Indonesia, khususnya dalam hal pendidikan luar kelas (outdoor education) dan seiringnya melemahnya karakter para siswa didik disekolah, sifat malas, kekerasan, dan kejenuhan akan sekolah, yang mencerminkan karater yang lemah dari siswa sekolah terutama sekolah dasar. Inilah yang melatarbelakangi penulis untuk mengetahui Implementasi Pendidikan Luar Sekolah (Outdoor Education) Terhadap Pembentukan Karakter Siswa Sekolah Dasar. 


\section{B. METODE}

\section{Pendekatan dan Metode Penelitian}

Dalam penelitian ini digunakan pendekatan kuantitatif dan kualitatif. Mixed methodology design (penelitian campuran) dipilih sebagai metode penelitian karena di dalamnya pendekatan kuantitatif dan pendekatan kualitatif dilakukan secara terpadu dan saling mendukung (Arikunto, 2006:11). Desain penelitian eksperimen yang digunakan dalam penelitian ini adalah nonequivalent pre test-post test control group design (pre test-post test dua kelompok). Salah satu pertimbangan yang digunakan dalam memilih desain ini adalah karena merupakan desain yang banyak digunakan dalam penelitian di bidang pendidikan. Skema penelitian dengan desain nonequivalent pre test-post test control group design (pre test-post test dua kelompok) adalah sebagai berikut :

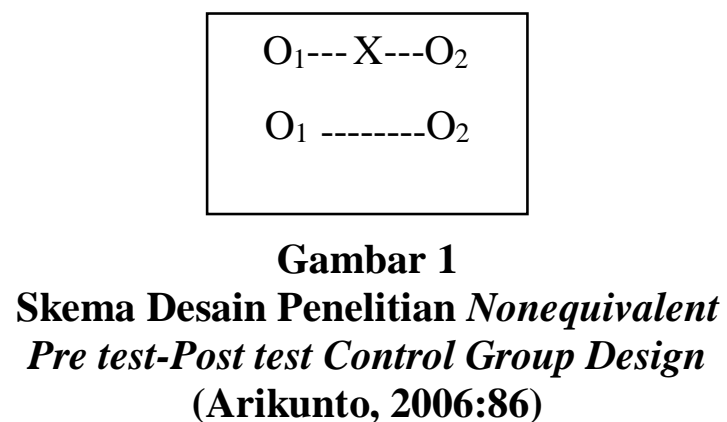

\section{Waktu dan Tempat Penelitian}

Penelitian berlangsung selama 8 bulan yakni terhitung dari bulan Maret 2016 sampai dengan Oktober 2016. Penelitian bertempat di sekolah dasar negeri Leuwigajah Mandiri 1 Cimahi Jawa Barat. Subjek penelitian yaitu siswa sekolah dasar negeri Leuwigajah Mandiri 1 Cimahi Jawa Barat.

\section{Instrumen Pengumpul Data}

\section{Variabel Pembentukan Nilai dan Karakter Siswa}

\begin{tabular}{|c|c|c|c|}
\hline \multicolumn{4}{|c|}{$\begin{array}{c}\text { Variabel Nilai } \\
\text { (Misbach, 2006:18) }\end{array}$} \\
\hline $\begin{array}{c}\text { Definisi } \\
\text { Konseptual }\end{array}$ & $\begin{array}{c}\text { Definisi } \\
\text { Oprasional }\end{array}$ & Sub Variabel & Indikator \\
\hline Tahap anatomi & $\begin{array}{l}\text { Tahap knowledge } \\
\text { dimana anak- }\end{array}$ & $\begin{array}{l}\text { Intellectual } \\
\text { Empathy }\end{array}$ & $\begin{array}{l}\text { Kejujuran, } \\
\text { Tenggang, rasa }\end{array}$ \\
\hline
\end{tabular}




\begin{tabular}{|c|c|c|c|}
\hline & $\begin{array}{l}\text { anak diajarkan } \\
\text { untuk memahami } \\
\text { perbedaan core } \\
\text { value }\end{array}$ & & \multirow{4}{*}{$\begin{array}{l}\text { Penghargaan } \\
\text { terhadap alam, } \\
\text { Konsep diri, } \\
\text { disiplin, } \\
\text { menghormati } \\
\text { aturan }\end{array}$} \\
\hline Tahap heteronomy & $\begin{array}{l}\text { Tahap nilai } \\
\text { berpotensial yang } \\
\text { dikembangkan } \\
\text { melalui aturan dan } \\
\text { pendisiplinan }\end{array}$ & $\begin{array}{l}\text { Nilai-Nilai } \\
\text { Budaya }\end{array}$ & \\
\hline Tahap sosionomi & $\begin{array}{lr}\text { Tahap } & \text { nilai } \\
\text { berkembang } & \text { di } \\
\text { tengah-tengah } & \text { teman } \\
\text { sebaya } & \text { dan } \\
\text { masyarakatnya } & \end{array}$ & Perilaku & \\
\hline Tahap otonomi & $\begin{array}{l}\text { Tahap nilai mengisi } \\
\text { dan mengendalikan } \\
\text { kata } \\
\text { hati dan kemauan } \\
\text { bebasnya tanpa } \\
\text { tekanan } \\
\text { lingkungannya. }\end{array}$ & $\begin{array}{l}\text { Pengendalian } \\
\text { Diri }\end{array}$ & \\
\hline \multicolumn{4}{|c|}{$\begin{array}{l}\text { Variabel Karakter } \\
\text { (Misbach, 2006:19) }\end{array}$} \\
\hline $\begin{array}{c}\text { Definisi } \\
\text { Konseptual }\end{array}$ & $\begin{array}{c}\text { Definisi } \\
\text { Operasional }\end{array}$ & Sub Variabel & Indikator \\
\hline Kognitif & $\begin{array}{l}\text { Pengetahuan } \\
\text { mengenai yang baik } \\
\text { dan buruk dengan } \\
\text { dasar rasional yang } \\
\text { akan memproses } \\
\text { secara kreatif } \\
\text { sebagai bahan } \\
\text { keputusan moral. }\end{array}$ & $\begin{array}{l}\text { Pengetahuan } \\
\text { rasional }\end{array}$ & 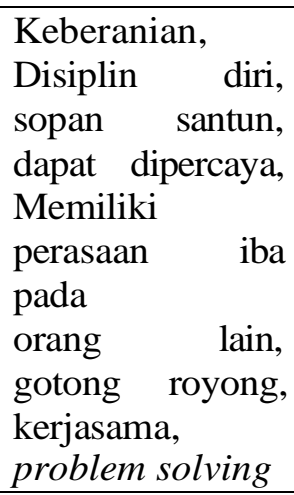 \\
\hline Afektif & $\begin{array}{l}\text { Pengetahuan yang } \\
\text { sudah tersimpan itu } \\
\text { akan mempengaruhi } \\
\text { nilai apa yang akan } \\
\text { tertanam } \\
\text { pada komponen } \\
\text { afektif, }\end{array}$ & Moral dan Etika & \\
\hline
\end{tabular}




\begin{tabular}{|c|c|c|c|}
\hline & $\begin{array}{l}\text { untuk menghasilkan } \\
\text { judgment } \\
\text { moral/etika }\end{array}$ & & \\
\hline $\begin{array}{l}\text { Kemauan } \\
\text { (volition) }\end{array}$ & $\begin{array}{l}\text { Komitmen ini } \\
\text { didasari } \\
\text { Pengetahuan } \\
\text { untuk mengetahui } \\
\text { nilai apa yang } \\
\text { dipelajari } \\
\text { berdasarkan } \\
\text { pengetahuan yang } \\
\text { telah tersimpan } \\
\text { sebelumnya }\end{array}$ & $\begin{array}{l}\text { Komitmen } \\
\text { perilaku baik dan } \\
\text { buruk }\end{array}$ & \\
\hline $\begin{array}{l}\text { Perilaku } \\
\text { (behavior) }\end{array}$ & $\begin{array}{l}\text { Mereflesikan } \\
\text { pengetahuan } \\
\text { nilai,kemauan } \\
\text { komitmennya } \\
\text { kedalam perilaku } \\
\text { aktualnya }\end{array}$ & Habit & \\
\hline
\end{tabular}

\section{PENGOLAHAN DAN ANALISIS DATA}

Pendekatan statistika yang digunakan untuk mengolah data yang nantinya diharapkan didapatkan kesimpulan dari hasil penelitian, penulis menggunakan metode statistika dengan uji kesamaan dua rata-rata (uji t satu pihak). Dengan menggunakan rumus ini diharapkan dapat memberikan jawaban mengenai rumusan masalah yang diajukan dalam penelitian, yaitu " Apakah terdapat implementasi pendidikan luar sekolah (Outdoor Education) terhadap pembentukan karakter siswa sekolah dasar ? "

Adapun Hipotesis yang diajukan adalah sebagai berikut:

Ho : $\mu_{1} \leq \mu_{2}$ tidak terdapat implementasi yang signifikan antara outdoor education terhadap pembentukan karakter siswa sekolah dasar.

Ha : $\mu_{1} \geq \mu_{2}$ terdapat implementasi yang signifikan antara outdoor education terhadap pembentukan karakter siswa sekolah dasar. 
Tabel 1

Hasil Analisis Uji Kesamaan Dua Rata-rata (Uji Satu Pihak) Karakter Kelompok Outdoor Education dan Non Outdoor Education

\begin{tabular}{|c|c|c|}
\hline $\mathbf{t}-$ Hitung & $\mathbf{t}-$ Tabel $(\alpha \mathbf{0 , 0 5})$ & Kesimpulan \\
\hline 4,67 & 1,743 & Ditolak \\
\hline
\end{tabular}

Kriteria:

Terima Ho jika $\mathrm{t}_{\text {hitung }} \leq \mathrm{t}_{1}-\alpha\left(\mathrm{n}_{1}+\mathrm{n}_{2}-2\right)$ dalam hal lain hipotesis ditolak

Tolak Ho jika $\mathrm{t}_{\text {hitun }} \geq \mathrm{t}_{1}-\alpha\left(\mathrm{n}_{1}+\mathrm{n}_{2}-2\right)$ dalam hal lain hipotesis diterima

Tolak hipotesis jika nilai $\mathrm{t}$ hitung $>\mathrm{t}$ tabel dimana diperoleh $\mathrm{t}$ tabel distribusi $\mathrm{t}$ dengan $(\alpha 0,05)$ dan $\mathrm{dk} \mathrm{n}_{1}+\mathrm{n}_{2}-2$. berdasarkan penghitungan diatas diperoleh $\mathrm{t}_{\text {hitung }}=4,67$ dan nilai $\mathrm{t}$ tabel $=1,743$ artinya hipotesis ditolak yang berarti bahwa terdapat implementasi positif yang signifikan dari pendidikan luar sekolah (Outdoor Education) terhadap pembentukan karakter siswa sekolah dasar.

\section{HASIL PENELITIAN}

Hasil penelitian menunjukan ada beberapa karakter yang diterapkan dalam pendidikan luar sekolah/outdoor education yang dapat membentuk karakter positif pada anak antara lain:.

1. Pertama, cenderung menggunakan atau memanfaatkan alat atau fasilitas di lingkungan kita tanpa harus membelinya sehingga perlu daya imajinasi dan kreativitas yang tinggi.

2. Kedua, meningkatkan kemampuan problem solving pada anak, menstimulasi perkembangan bahasa dan kemampuan verbal, mengembangkan keterampilan sosial, dan merupakan wadah pengekspresian emosi.

3. Ketiga, sebagai sarana menumbuhkan kemampuan sosialisasi pada anak. Bermain memungkinkan anak untuk berinteraksi dengan lingkungan sosialnya yang dapat mengajarkan anak untuk mengenal dan menghargai orang lain.

4. Keempat, sebagai sarana mengembangkan kemampuan dan potensi anak. Bermain dapat memungkinkan anak untuk mengenali berbagai macam benda, mengenali sifatnya, serta peristiwa yang terjadi di lingkungannya.

5. Kelima, menilik nilai-nilai luhur dan pesan-pesan moral tertentu seperti nilai-nilai kebersamaan, kejujuran, tanggung jawab, sikap lapang dada (kalau kalah), dan taat pada aturan.

Penelitian dan aplikasi mengenai outdoor education sudah banyak dilakukan di negara-negara lain. Sama seperti di Indonesia, outdoor education yang diterapkan di negara-negara lain pun diharapkan dapat menumbuhkan nilai-nilai yang dapat bermanfaat bagi kehidupan murid dimasa yang akan datang. Sebagai contoh, Singapura adalah salah satu negara yang memasukkan outdoor education di dalam sistem pendidikan mereka sejak bertahun-tahun yang lalu (Wang, Liu, \& Khalid, 
2006). Walaupun outdoor education tersebut tidak masuk ke dalam kurikulum formal dan jenisnya disesuaikan dengan karakter masing-masing sekolah, akan tetapi setiap siswa diharapkan untuk ikut kegiatan kemping setidaknya 2 kali dalam setiap empat tahun masa sekolah (Shanmugaratnam, 2004). Penelitian-penelitian yang telah dilakukan, mengungkapkan bahwa outdoor education meningkatkan daya juang dan keinginan untuk maju pada siswa di Singapura (Shanmugaratnam, 2004), selain terbukti mengkatkan kesehatan dan kebugaran (Lui, 2006). Lebih jauh lagi, ternyata outdoor education dapat meningkatkan kecintaan terhadap tanah air bagi para siswa di Singapura (Stewart, 2003) (Orr, 2005b, p. 106), karena dengan outdoor education, siswa diajak untuk mengenal lebih jauh lingkungan, alam, dan sejarah yang ada dibaliknya. Hal tersebut lalu bisa mengarah kepada literasi ekologi.

Di Selandia Baru, Mike Brown mengungkapkan bahwa yang tidak kalah penting dalam merancang ourtdoor education adalah mengenai pilihan lokasi. Dalam artikelnya yang berjudul "Developing a place-based approach to outdoor education in Aotearoa New Zealand", dia mengungkapkan bahwa dengan melakukan outdoor education di lingkungan yang dekat dengan tempat tinggalnya, baik guru maupun siswa sama-sama akan mendapatkan manfaat, yaitu biaya yang lebih terjangkau dan terciptanya hubungan yang kuat antara guru dan murid selama proses perjalanan. Ini menjadi dasar bahwa untuk membuat program Outdoor education, tidak membutuhkan biaya yang besar, akan tetapi dapat dilakukan di lingkungan sekitar sekolah sehingga juga dapat menyerap aspek-aspek kearifan lokal.

Dari paparan yang sudah dikemukakan, outdoor education dapat dihubungkan dan diaplikasikan untuk mencapai berbagai tujuan yang sudah dicanangkan sebelumnya. Dapat saja tujuan ini dihubungkan dengan masalah kecintaan terhadap tanah air, penanggulangan masalah lingkungan, penanganan terhadap rendahnya kemampuan untuk bertahan di alam bebas, dan sebagainya. Mempertimbangkan hal tersebut, penelitian-penelitian mengenai outdoor education sebaiknya dilakukan lebih luas lagi dengan latar belakang alam, budaya dan adat yang lebih bervariasi lagi, sehingga akan menambah referensi bagi pelaksanaan outdoor education di sekolah- sekolah.

\section{E. KESIMPULAN}

Berdasarkan hasil pengolahan dan analisis data, disimpulkan bahwa nilai-nilai pendidikan luar sekolah (outdoor education) sebagai landasan/pondasi pembentukan karakter siswa. Bagi para guru Penjas, hendaknya memahami dan menerapkan pendidikan luar sekolah (outdoor education) sebagai salah satu uapaya pembentukkan karakter melalui pembelajaran penjas di sekolah. Bagi para siswa Leuwigajah Mandiri 1 Cimahi, agar memiliki kesadaran yang tinggi tentang pentingnya olahraga untuk kesehatan, sehingga siswa memiliki motivasi yang tinggi untuk berpartisipasi didalam pembelajaran penjas dan menyadari nilai dasar yang terkandung dalam pendidikan jasmani. Bagi lembaga diharapkan hasil penelitian ini menjadi sumbangan ilmu pengetahuan yang akan bermanfaat bagi semua pihak dan penulis berharap 
kepada pihak lembaga agar penelitian ini dilakukan kembali dengan sampel yang lebih besar guna menghasilkan penelitian yang makin baik dari sebelumnya. 


\section{REFERENSI}

Arikunto, S. (2006). Prosedur Penelitian. Jakarta : Rineka Cipta.

Anggani S. 2000. Sumber Belajar dan Alat Permainan. Jakarta. Grasindo

Arief Komarudin, 2000. Pojok Penjas:

http://pojokpenjas.blogspot.com/2007/12/babipendahuluanrasional.htm

Brown.2012. Developing a place-based approach to outdoor education in Aotearoa New Zealand.

Fince Herry. 2008. Membangun Pendidik Alam (pioda.multiply.com/reviews/item/1-29k.) diakses pada 28 -92008 pukul 08.28 wib

Goleman D. 2000. Emotional Intelgence. Jakarta: Gramedia Pustaka Utama.

Ho,Susan. 2014. The purposes outdoor education does, could and should serve in Singapore. Journal of Adventure Education and Outdoor Learning . http://www.tandfonline.com/loi/raol20 (http://www.bpkp.go.id/index.php?idpage=2027\&idunit=24) http://www.plbjabar.com/?inc=artikel\&id=40. diakses pada $28 \mathrm{Mei}$ 2008

Lui, T. Y. (2006). Opening address by Minister of State, MOE, at the 2nd Outdoor Education Conference on 31 Oct. Retrieved from http://www.moe.gov.sg/speeches/2006/sp20061031.htm

Maya I, 2008. Makalah. Out Bond menjadi Salah Satu Pendidikan Luar Kelas. Yogyakarta: UNY

Megawangi R. 2007. Jangan remehkan Pengasuhan Otak Anak. http://www.Pendidikankarakter.edu. Diakses pada 21 Mei 2008

Mitchell dan Meier. 1983. Camp Counselling. USA: CBS College Publising.

Orr, D. (2005a). Foreword. In M. K. Stone \& Z. Barlow (Eds.), Ecological literacy: Educating our children for a sustainable world (pp. ix-xii). San Francisco, CA: Sierra Club Books.

Shanmugaratnam, T. (2004). Speech by Acting Minister for Education at the 45th General Meeting of the Singapore Schools Sports Councils on 17 Jan. Retrieved from http://www.moe.gov.sg/speeches/ 2004/sp20040117.html 
Stewart, A. (2003). Reinvigorating our love of our home range: Exploring the connections between sense of place and outdoor education. Australian Journal of Outdoor Education, 7(2), 19-26.

Tri IL. 2008. Makalah: Upaya Meningkatkan Motivasi Belajar Siswa Melalui Pendidikan Luar Kelas. FIK UNY

Vincencia S, 2006. Mendidik Generasi Muda dengan Pendidikan Lingkungan: http:/rafflesia.wwf.or.id/library/clips/clips_detil.php?id_clips=20

Wang, C. K. J., Liu, W. C., \& Khalid, A. (2006). Effects of a five-day Outward Bound course on female students in Singapore. Australian Journal of Outdoor Education, 10(2), 20-28. 